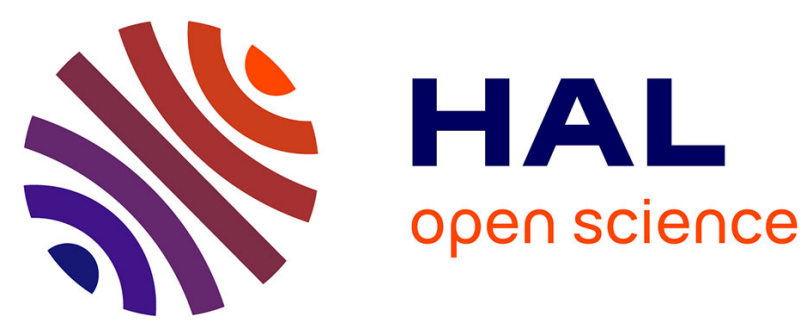

\title{
Influence of Mechanical Surface Treatment on High-Temperature Oxidation of Pure Titanium
}

Armand Kanjer, Virgil Optasanu, Luc Lavisse, María del Carmen Marco de

Lucas, Steeve Dejardin, Manuel François, Pascal Berger, Patrice Peyre, Cyril Gorny, Tony Montésin

\section{To cite this version:}

Armand Kanjer, Virgil Optasanu, Luc Lavisse, María del Carmen Marco de Lucas, Steeve Dejardin, et al.. Influence of Mechanical Surface Treatment on High-Temperature Oxidation of Pure Titanium. Oxidation of Metals, 2017, 88 (3-4), pp.383-395. 10.1007/s11085-016-9700-6 . hal-02165205v2

\section{HAL Id: hal-02165205 \\ https://hal.science/hal-02165205v2}

Submitted on 27 Sep 2019

HAL is a multi-disciplinary open access archive for the deposit and dissemination of scientific research documents, whether they are published or not. The documents may come from teaching and research institutions in France or abroad, or from public or private research centers.
L'archive ouverte pluridisciplinaire HAL, est destinée au dépôt et à la diffusion de documents scientifiques de niveau recherche, publiés ou non, émanant des établissements d'enseignement et de recherche français ou étrangers, des laboratoires publics ou privés. 


\title{
Influence of Mechanical Surface Treatment on High- Temperature Oxidation of Pure Titanium
}

\author{
Armand Kanjer ${ }^{1} \cdot$ Virgil Optasanu $^{1}$ (D) Luc Lavisse ${ }^{1}$ • \\ María del Carmen Marco de Lucas $^{1} \cdot$ Steeve Dejardin $^{1}$. \\ Manuel François ${ }^{2} \cdot$ Pascal Berger $^{3}$ - Patrice Peyre ${ }^{4}$. \\ Cyril Gorny $^{4} \cdot$ Tony Montesin ${ }^{1}$
}

\begin{abstract}
The excellent combination of light-weight and good mechanical properties makes titanium alloys attractive for compressor section components in gas turbine engines (temperature between 250 and $600{ }^{\circ} \mathrm{C}$ ). However, above $600{ }^{\circ} \mathrm{C}$, the formation of an unprotective oxide layer facilitates the oxygen diffusion into the alloy. In this experimental study, pure titanium was treated with mechanical surface treatment to promote better protection against oxidation at high temperature. Shotpeened and laser-shock peened specimens were compared to untreated samples in terms of oxidation behavior at high temperature. We used thermal gravimetric analysis to oxidize the samples at $700{ }^{\circ} \mathrm{C}$ for $100 \mathrm{~h}$. Subsequently, XRD, optical microscopy, SEM/EDS, NRA, micro-Raman spectroscopy, and micro-hardness were used to characterize the oxide scale and the alpha-case layer formed during the high-temperature exposure. The shot-peened samples oxidized less $(-45 \%)$ than the untreated and laser-shock peened samples. This behavior was attributed to the formation of a continuous nitride layer between oxide and metal.
\end{abstract}

\footnotetext{
Virgil Optasanu

virgil.optasanu@u-bourgogne.fr

Armand Kanjer

armand.kanjer@u-bourgogne.fr

Tony Montesin

tony.montesin@u-bourgogne.fr
}

1 Laboratoire Interdisciplinaire Carnot de Bourgogne (ICB), UMR 6303 CNRS-Université Bourgogne Franche-Comté, 9 Av. A. Savary, BP 47870, 21078 Dijon Cedex, France

2 Institut Charles Delaunay (ICD)/LASMIS, UMR 6281 CNRS - Université de Technologie de Troyes, 12 rue Marie Curie, CS 42060, 10004 Troyes Cedex, France

3 CEA-Saclay, CEA/IRAMIS/NIMBE/LEEL UMR CEA-CNRS3685, 91191 Gif sur Yvette, France

4 PIMM Laboratory, UMR 8006 CNRS - Arts et Métiers ParisTech, 151 Bd de l'Hôpital, 75013 Paris, France 
Keywords Titanium $\cdot$ High-temperature oxidation $\cdot$ Shot-peening $\cdot$ Laser-shock peening

\section{Introduction}

The improvement of aeronautic turbine requires development of material weight, efficiency, and sustainability. The excellent coupling between lightness and good mechanical properties allows the titanium alloys attractive for production of parts integrating the compressor section of turbine [1]. High-temperature oxidation can lead to catastrophic failures and impose the use of high-performance coatings or surface treatment to protect the integrity of the parts. Titanium and titanium-based alloys offer the potential for component weight savings in the order of $50 \%$ compared to super alloys of $\mathrm{Ni}$ and steels. At the beginning of oxidation, the passivation layer grows and brings to the formation of unprotective oxide layer [2]. This unprotective scale facilitates the inward flux of oxygen and then permits its diffusion into the metal. The diffusion area, also called $\alpha$-case, presents high hardness but low ductility. Moreover, some authors noticed also the presence of nitrides during high-temperature oxidation of pure titanium [3, 4].

Several attempts were made to develop suitable oxidation-resistant coating for titanium alloys. Chemical treatments are the most used for oxidation protection with pack cementation coatings [5, 6], ion implantation [7, 8], PVD ceramic coatings $[9,10]$. Mechanical treatments are generally rather used to improve the tribological and mechanical surface properties [11]. Recent works [12, 13] show that large compressive stresses as well surface hardening play also a positive role in the oxidation resistance of materials.

This work investigates the influence of mechanical surface treatment by shotpeening and laser-shock peening on the high-temperature oxidation resistance of commercial pure titanium. A comparison between treated and untreated samples is led in term of oxidation resistance at $700{ }^{\circ} \mathrm{C}$ in dry air. The resistance in term of oxidation kinetics is studied by thermo-gravimetric analysis (TGA) for $100 \mathrm{~h}$ of oxidation. Subsequently, the surface modifications as well the oxide and alpha-case layers were analyzed by X-ray diffraction (XRD), optical microscopy, scanning electron microscopy coupled with energy-dispersive detector (SEM/EDS), microRaman spectroscopy, micro-hardness, and nuclear reaction analysis (NRA).

\section{Experimental Procedures}

The material used in this study was commercially pure titanium $(99.6 \%$, Goodfellow). The composition (in wt $\%$ ) is the following: Ti bal., Fe 0.06, O 0.05, Co 0.03, Ni 0.023, Cr 0.018, C 0.011, Sn 0.01, Mo 0.01, Si 0.01. It is a typical grade II material. This material was annealed to recrystallize after forming. After annealing, the grain size was approximately $35 \mu \mathrm{m}$. The size of samples used for 
mechanical and laser treatments was $25 \times 50 \times 1 \mathrm{~mm}^{3}$. For TGA purposes, the samples were cut in small pieces $\left(8 \times 10 \times 1 \mathrm{~mm}^{3}\right)$.

The mechanical surface treatments were performed using two different methods. The first one is shot-peening by surface mechanical attrition treatment (SMAT) with WC balls of $2 \mathrm{~mm}$. This method consists of vibrating WC balls in a closed chamber using high-power ultrasound $(20 \mathrm{kHz}$ of frequency). The balls projected on the sample surface induce large residual compressive stresses, strong plastic strains, and a nano-structuration of the sub-surface of the material $[14,15]$. The height of the chamber is $15 \mathrm{~mm}$ and the amplitude of vibration during the treatment is $12 \mu \mathrm{m}$. The samples were treated during $30 \mathrm{~min}$ by face with reversing of the treated face each $10 \mathrm{~min}$ in order to keep the Almen's strains reasonable. Further, in this text, the 30 min shot-peened sample will be called SP30.

The second treatment studied here is the laser-shock peening. The laser used here is GAIA HP. This method consists of sending high intensity laser short impulsions on the surface sample. An adhesive aluminum film is pasted on the surface of the sample to protect it against thermal effects or oxidation of the titanium in contact with the water. The laser shock frequency was $0.5 \mathrm{~Hz}$ and the pulse duration was $7 \mathrm{~ns}$. The laser irradiance used here was $9.1 \mathrm{GW} / \mathrm{cm}^{2}$. The laser scanned the sample surface with a velocity of $1.1 \mathrm{~mm} / \mathrm{s}$. This leads to an overlapping area of $30 \%$ between two successive impacts. For such laser irradiance, each impact generates a plasma plume over the target. The plasma extinction generates a shock wave into the target. The treatment was operated in water to increase the shock amplitude $[16,17]$. Further in this text the laser-shock peened sample will be called LSP.

The oxidation kinetics was studied by isothermal TGA using SETSYS EVOLUTION 1750 by SETARAM. The experiments were performed at $700{ }^{\circ} \mathrm{C}$ during 5, 10 and $100 \mathrm{~h}$ under dry air and $100 \mathrm{~h}$ under pure oxygen. A ramp of $10{ }^{\circ} \mathrm{C} / \mathrm{min}$ was used to go from room temperature to $690{ }^{\circ} \mathrm{C}$, followed by a lower ramp of $1{ }^{\circ} \mathrm{C} / \mathrm{min}$ to reach $700{ }^{\circ} \mathrm{C}$.

After treatment and oxidation, the phase constituents were analyzed by X-ray diffraction and micro-Raman spectroscopy. XRD patterns were obtained with a Bruker D8-A25 DISCOVER goniometer using $\mathrm{Cu}-\mathrm{K}_{\alpha}$ radiation. Micro-Raman spectra were obtained with a Renishaw InVia set-up in backscattering configuration. The wavelength used was $532 \mathrm{~nm}$ and the excitation power focused on the sample was about $0.5 \mathrm{~mW}$ to avoid heating the samples.

The morphology of the treated samples was analyzed by optical polarized microscopy (Olympus BX 60) and SEM with an EDS analyzer (TESCAN VEGA 3). We also used SEM to investigate the morphology and the thickness of the oxide scale and $\alpha$-case area.

Nuclear reaction analysis (NRA) was used to study the presence of nitrogen in the oxidized treated samples. This technique is designed for detection and quantification of light elements by analyzing the nuclear reactions after interaction with ionized deuterons [18]. The beam energy was set to $1900 \mathrm{keV}$ in order to detect nitrogen. Several nuclear reactions between deuterium ions and nitrogen isotope ${ }^{14} \mathrm{~N}$ take place. The reaction ${ }^{14} \mathrm{~N}\left(\mathrm{~d}, \alpha_{1}\right){ }^{12} \mathrm{C}$ produces backscattered alpha particles and the isotope ${ }^{12} \mathrm{C}[19]$. 
The micro-hardness was measured in cross section of the samples using a ZWICK/ROELL ZHV $\mu$ micro-hardness tester with Vicker's diamond pyramid indenter and a load of $50 \mathrm{gf}$ after treatments and $25 \mathrm{gf}$ for $\alpha$-case depth determination during $10 \mathrm{~s}$.

\section{Results}

A comparison between untreated, SP30 and LSP samples is presented Fig. 1. Optical and SEM microscopic images show strong deformation of the sub-surface layers. The thickness affected is about $190 \mu \mathrm{m}$ for SP30 (white arrows). The grains near to the surface present twinnings and their size seems smaller than the untreated samples. For LSP, the whole thickness sample is affected by the treatment. Almost all the grains present twinnings but in comparison with shot-peened sample, no grain refinement appears.

The measures hardness of the raw material was $135 \mathrm{HV}$. Micro-hardness profiles made on SP30 samples cross section show strong gradients going from 215 (at the surface) to $135 \mathrm{HV}$ (at the core of the material) on $\sim 200 \mu \mathrm{m}$. At the extreme surface, the hardness increase is about $80 \mathrm{HV}$. By comparison, the untreated and LSP samples present no gradient of hardness. However, a slight all-over increase of about $\sim 15 \mathrm{HV}$ was remarked on the LSP samples.

In order to measure the defects recovering, hardness measurements after annealing under vacuum conditions were realized. After $1 \mathrm{~h}$ at $700{ }^{\circ} \mathrm{C}$, the grain size recovers to original values and the defects recovering is complete since the hardness drops down to raw metal values.

Figure 2a shows the XRD patterns before and after treatment. Titanium alpha phase was detected for all the samples, but for the SP30 sample, a second phase was detected: hexagonal tungsten carbide, WC. This evidences the pollution due to the balls used for SP treatment. On the other hand, as expected, no pollution was detected on LSP samples. A broadening of the diffraction peaks is observed in the

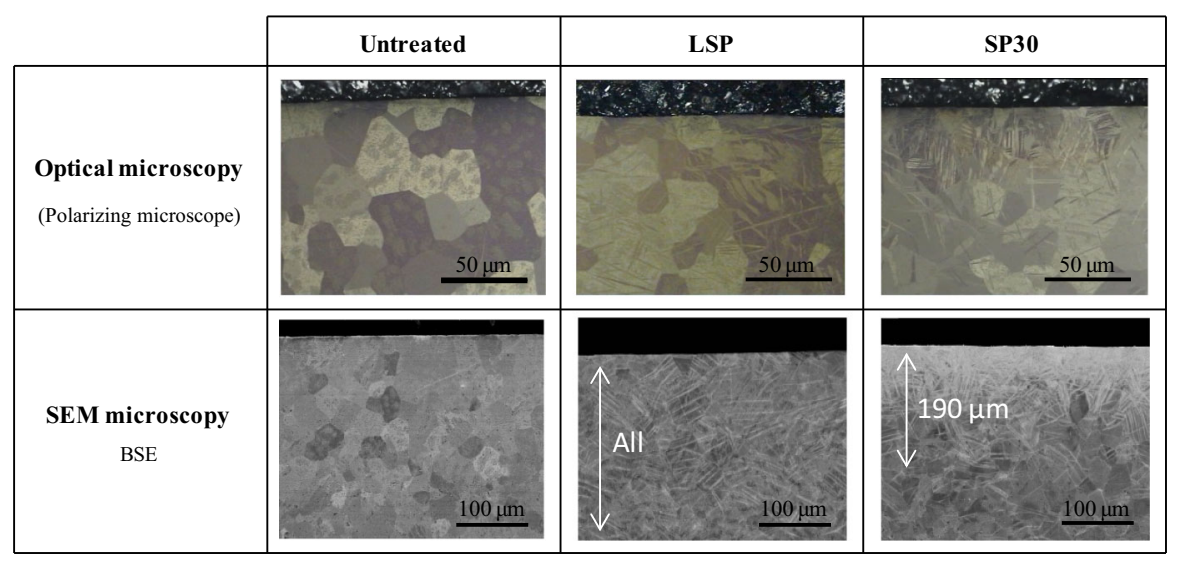

Fig. 1 Cross-section and surface images of untreated and treated samples 


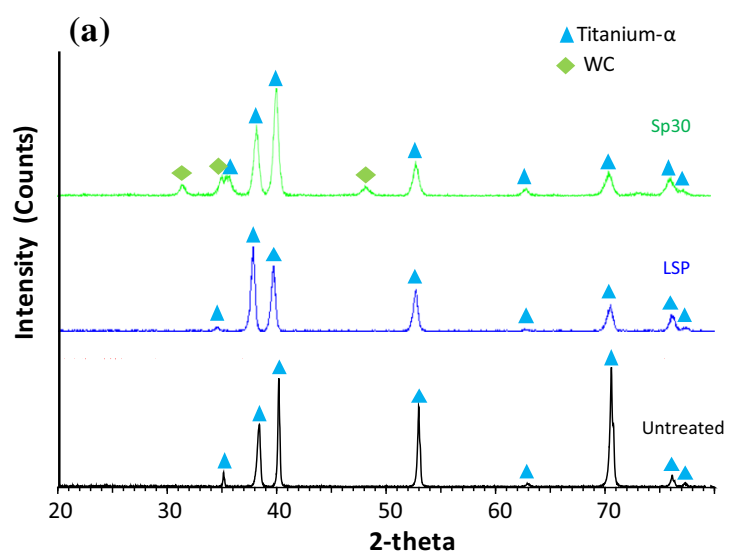

(b)

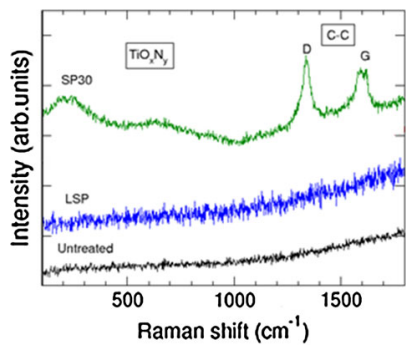

Fig. 2 a XRD patterns and b Raman spectra of samples (Color figure online)

case of SP30 and LSP, which demonstrates the introduction of defects and/or a grain refinement. Moreover, the relative height of the peaks shows a slightly different texture on the SP30 and LPS sample compared to two others samples. It means that there are probably differences in the density of the superficial layers of LSP and SP30 compared to untreated samples.

Figure $2 \mathrm{~b}$ displays the Raman spectra obtained for the same samples. No Raman bands were found for untreated samples (black curve) as well as for LSP (blue curve). On the contrary, the spectra of SP30 display several bands in the $100-1800 \mathrm{~cm}^{-1}$ range. First, very weak broadbands at about 210 and $640 \mathrm{~cm}^{-1}$ can be assigned to under-stoichiometric titanium oxides, or oxynitrides $\left(\mathrm{TiO}_{x} \mathrm{~N}_{y}\right)$ [20]. Moreover, the spectra display two bands at 1340 and $1600 \mathrm{~cm}^{-1}$, which can be assigned to carbon-carbon vibrational modes (D and G modes, respectively) [21]. They reveal the presence of a pure carbon phase due to the contamination of the sample surface during the shot-penning process. Finally, it is worth noting that WC has no Raman-allowed vibrational modes due to its NaCl-type structure.

Oxidation tests were made using TGA under controlled temperature and atmospheres. Figure 3 presents the oxidation kinetic curves after $100 \mathrm{~h}$ of oxidation under (a) synthetic air (air) and (b) pure oxygen $\left(\mathrm{O}_{2}\right)$ at $700{ }^{\circ} \mathrm{C}$. Under dry air, the superposition shows for all treated samples a mass gain reduction during isothermal oxidation by comparison the untreated reference. The difference is about $10 \%$ for LSP and $45 \%$ for SP30 compared to untreated pure Ti. Under pure oxygen $\left(\mathrm{O}_{2}\right)$, the superposition shows a breakaway during isothermal oxidation for all samples: after about $80 \mathrm{~h}$ for the untreated sample, $90 \mathrm{~h}$ for the LSP, and $65 \mathrm{~h}$ for the SP30. Moreover, the mass gain reduction for untreated and SP30 is considerably increased by comparison with oxidation under air. The main explanation can be the oxygen partial pressure, which is five times bigger in pure oxygen. On the other hand, the difference in mass gain for LSP under air and pure oxygen is smaller.

The following model can be used to describe the oxidation kinetics (Eq. 1): 
(a)

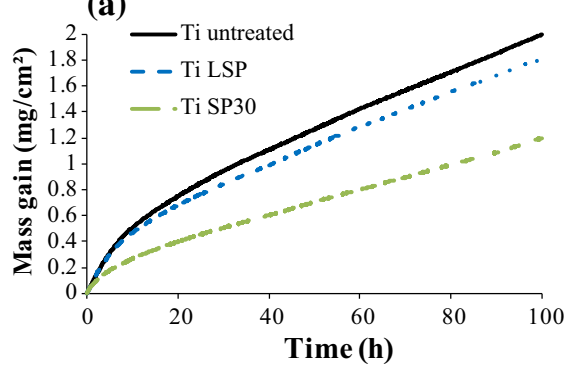

(b)

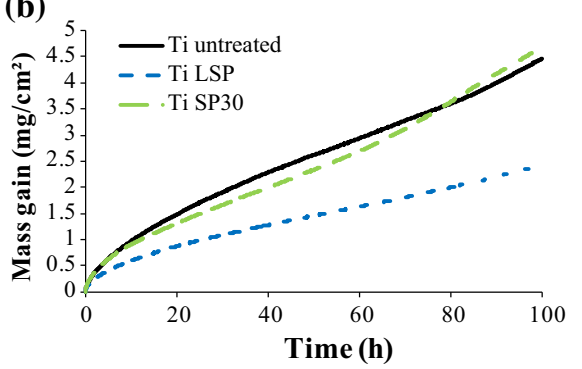

Fig. 3 Kinetic curves for treated and untreated samples after oxidation at $700{ }^{\circ} \mathrm{C}$ during $100 \mathrm{~h}$ in a dry air and $\mathbf{b}$ pure oxygen

$$
\left(\frac{\Delta m}{S}\right)=(k t)^{\frac{1}{n}}
$$

$\Delta m$ is mass variation, $S$ the surface size of the sample, $t$ the time, $k$ the oxidation constant, and $n$ a power index.

Three sections can be delimited from dry air oxidations curves:

- The first section (between 0 and $7.5 \mathrm{~h}$ for LSP and untreated or 0 and $0.6 \mathrm{~h}$ for SP30 samples) reveals a value of $n$ near 1 , which is typical for a rate-limiting step related to the reaction at the interface metal/oxide. The oxygen penetrates the metal more rapidly at the beginning in SP30 samples compared to the pure $\mathrm{Ti}$ and to LSP. This can be explained by the nanostructure of the superficial layer produced by the shot-peening, which increases the reactivity of the material.

- The second section (between 7.5 and $42 \mathrm{~h}$ for untreated and LSP samples or, respectively, between 0.6 and 42 h for SP30) shows a value of $n$ near 2, which corresponds to a rate-limiting process given by the diffusion of the oxygen through a dense, protective layer.

- For the third section (between 42 and $100 \mathrm{~h}$ ), the value of $n$ slightly decreases to 1.6 for LSP and untreated samples and, respectively, 1.4 for SP30. The diminution of the value of parameter $n$ tends to show that the oxide layer is constituted of an internal dense layer and an external cracked scale.

A variation between 1 and 2 is observed for the parameter $n$ during the different oxidations. The values of parameter $n$ are the combination of three events that interfere during oxidation time: layer oxide growth, inward oxygen diffusion into metal, and stratification of layer oxide. Depending on type of treatment, this value changes more or less rapidly with the different contributions of these three interferences. Generally, these curves are sub-parabolic. As noticed by Evans [22], stressed oxides tend to produce sub-parabolic rates of reaction, which is commonly observed on oxidation systems with Pilling-Bedworth ratio superior to one.

Table 1 presents the XRD results after short $(5 \mathrm{~h})$ and long $(100 \mathrm{~h})$ oxidation tests under dry air. For $100 \mathrm{~h}$ of oxidation, the rutile $(\mathrm{R})$ phase of $\mathrm{TiO}_{2}$ is the only phase detected for untreated and LSP, whereas the anatase (A) phase of $\mathrm{TiO}_{2}$ is 
Table 1 Different phase detected by XRD analysis after different oxidation times

\begin{tabular}{llll}
\hline & Untreated & LSP & $\mathrm{SP30}$ \\
\hline $5 \mathrm{~h} / 700{ }^{\circ} \mathrm{C} /$ air & $\mathrm{R} \mathrm{Ti}_{2} \mathrm{~N} / \mathrm{TiN}_{0.176}$ & $\mathrm{R} / \mathrm{Ti}_{2} \mathrm{~N} / \mathrm{TiN}_{0.176}$ & $\mathrm{WO}_{3} / \mathrm{A} / \mathrm{R} / \mathrm{Ti}_{2} \mathrm{~N} / \mathrm{TiN}_{0.176}$ \\
$100 \mathrm{~h} / 700{ }^{\circ} \mathrm{C} /$ air & $\mathrm{R}$ & $\mathrm{R}$ & $\mathrm{A} / \mathrm{R}$ \\
\hline
\end{tabular}

found also for SP30 for $5 \mathrm{~h}$ of oxidation, besides $\mathrm{TiO}_{2}$ phases, the formation of nitride is detected: $\mathrm{Ti}_{2} \mathrm{~N}$ and $\mathrm{TiN}_{0.176}$ for all treatments. Finally, XRD peaks assigned to hexagonal $\mathrm{WO}_{3}$ appear for SP30.

Figure 4 displays the Raman spectra obtained for the same samples after dry air oxidation during $5 \mathrm{~h}$. All the samples show intense Raman bands due to the rutile phase of $\mathrm{TiO}_{2}$. Furthermore, the presence of the anatase phase is also found for SP30, in good agreement with XRD results. Moreover, very strong Raman peaks due to hexagonal $\mathrm{WO}_{3}$ [23] were also found for SP30 in few different areas of the sample's surface.

Figure 5 shows cross-section SEM images of untreated and treated samples after oxidation during $100 \mathrm{~h}$ of exposure at $700{ }^{\circ} \mathrm{C}$ under dry air. For untreated sample and LSP, the thicknesses are similar (about 11 and $10 \mu \mathrm{m}$ ). The thickness of the oxide layer is sensibly smaller for SP30 $(5.5 \mu \mathrm{m})$. Stratification is observed on untreated samples. Stratification is less important for LSP treatment.

NRA analysis of cross-section samples was used to investigate the in-depth insertion of nitrogen. The bright thick layer shown in NRA maps (Fig. 5) reveals a nitrogen-rich area located between the oxide and the $\alpha$-case. This layer is not continuous for the untreated sample. On the contrary, for SP30 and LSP, the formation of a continuous nitride layer is observed. NRA maps show also a small signal due to nitrogen in the resin (which contains nitride aromatic heterocycles). One should notice that some nitrogen was detected also in smaller quantities in the LSP oxide layer and probably in the SP30 oxide layer (but is difficult to certificate this because of the small size of the oxide in that last case). Then, formation of oxynitrides is possible in LSP and SP30.

Fig. 4 Raman spectra of untreated and treated samples after oxidation during $5 \mathrm{~h}$ at $700{ }^{\circ} \mathrm{C}$ under dry air. Two spectra obtained for different areas of the sample surface are given for SP30

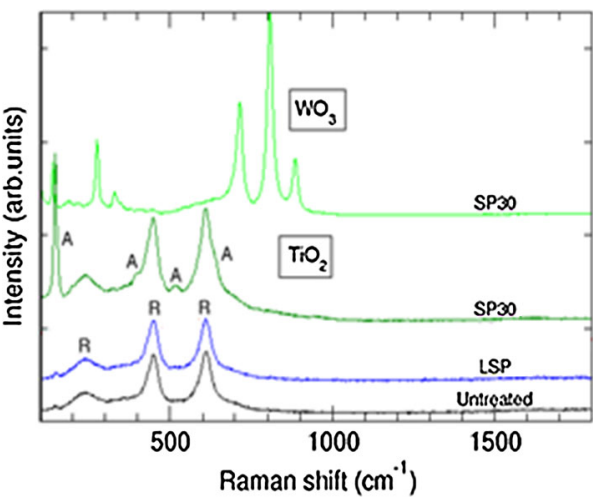




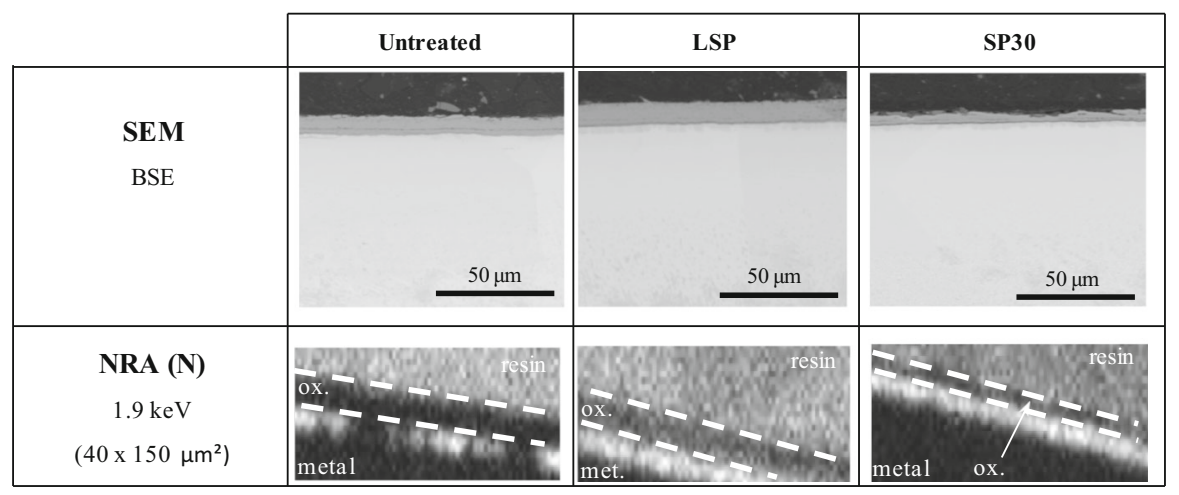

Fig. 5 Comparison of samples after oxidation under dry air at $700{ }^{\circ} \mathrm{C}$. In SEM images, the black upper part is the coating resin. For the NRA images, the oxide is located between the white dashed lines, and the metal is under the lower line

The $\alpha$-case area depth is measured by micro-hardness, and the results are presented (Fig. 6). For US, LSP, and SP30 samples the thickness of the $\alpha$-case are $\sim 65, \sim 60$, and respectively, $\sim 75 \mu \mathrm{m}$. This shows a bigger diffusion coefficient for the SP30, which can be explained by the high density of short-circuits diffusion paths. Also, as remarked by EDS measurements, next to the interface metal/oxide, the quantity of the dissolved oxygen is larger in the untreated case than in the LSP and SP30. This tends to confirm the role of barrier for the oxygen diffusion played by the nitrides located at the interface (Fig. 5).

\section{Discussion}

Figure 7 presents a schematic picture of the cross section for untreated, LSP and SP30 samples. The surface modification after treatment is different between LSP and SP. For LSP (Fig. 7b), the whole depth is impacted by the treatment. The short

Fig. 6 Micro-hardness measurements of $100 \mathrm{~h}$ oxidized samples at $700{ }^{\circ} \mathrm{C}$ under dry air

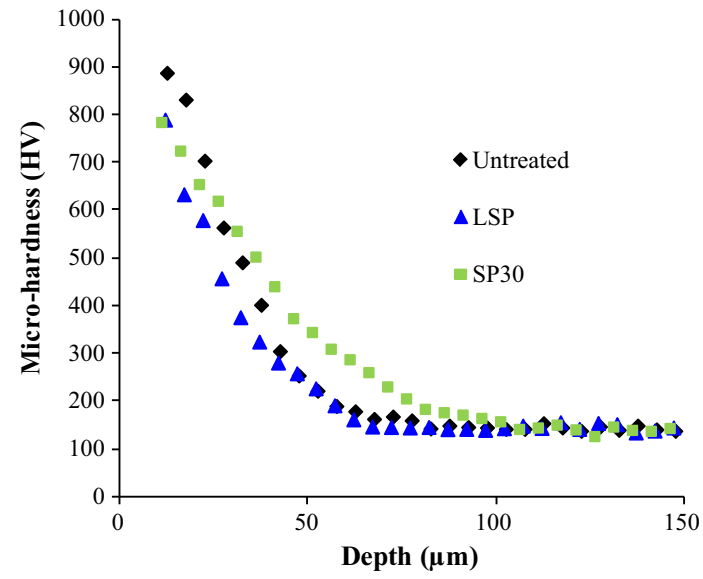


(a)

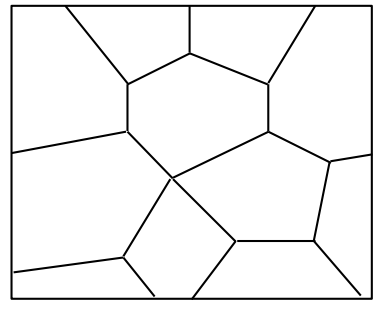

(b)

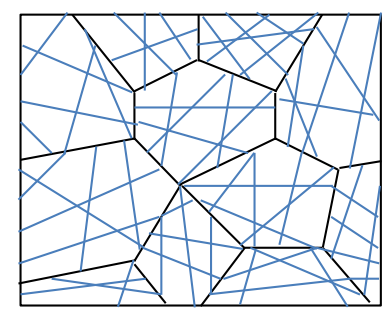

(c)

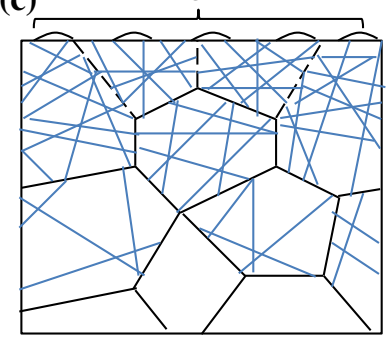

Fig. 7 Schematic cross-section representation: a untreated, b LSP and c SP30. Blue lines correspond to twins (Color figure online)

time of impact is insufficient to create a grain refinement of the microstructure. The shock wave penetrates in the material, and then is reflected several times, and finally affects the entire depth. In this case, twinning is the only mechanism of material destructuration. The hardness measurements show a small work hardening but a homogeneous repartition, contrary to SP samples. By consequence, the laser-shock peening gives more homogeneous structures than the shot-peening. In the literature, the authors were interested to perform laser-shock on other Ti alloys like Ti 834 [24], TC-11 [25], or TA6V [26]. They measured small increase of hardness after laser-shock peening (about $30 \mathrm{HV}$ for Ti 834 and TC-11 and about $45 \mathrm{HV}$ for TA6V). Jia et al. [24] show a refinement of the grains at the surface of the alloy. It is possible that the thickness of the material plays an important role for this type of treatment. Cellard et al. [27] show a strong difference on residual stress values with laser-shock peened treatment on 1 and 3 mm-thick Ti-17 plates. XRD and Raman (Fig. 2) detect no pollution after treatments.

For SP30 (Fig. 7c), only the surface is affected (about $200 \mu \mathrm{m}$ ). The intensity of the microstructural modifications decreases with the depth. The concentration of the twinning as well the grains refinement is decreasing from the surface to the core of the material. The hardness measurements indicate strong work-hardening and plastic strains near the surface of the sample. Other authors [14, 28, 29] also observed grain refinement and hardness increasing (depending of treatment's time and parameters). Zhu et al. [14] have studied the microstructure at different depth after SMAT treatment. A mechanism was proposed with, in a first time, a twinning of the grains by activation of slip plane and, in a second time, a refinement of the grains. XRD and Raman (Fig. 2) analyses prove some pollution by WC clusters after treatments.

Figure 8 presents a schematic picture of the cross section for oxidized samples $\left(100 \mathrm{~h}, 700{ }^{\circ} \mathrm{C}\right.$ under dry air) for untreated, laser-peened, and shot-peened samples.

Thick oxide layer and $\alpha$-case area depth are noticed for untreated samples (presented schematically Fig. 7a). The spallation and stratification of the oxide layer was also observed. NRA analysis (Fig. 5) shows the formation of non-continuous nitride layer between the oxide layer and $\alpha$-case area. For LSP samples (presented schematically Fig. 7b), the oxide thickness is about $10 \%$ smaller than of untreated samples. The $\alpha$-case area was reducing comparing to untreated sample. Better 
(a)

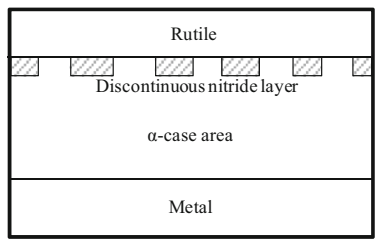

(b)

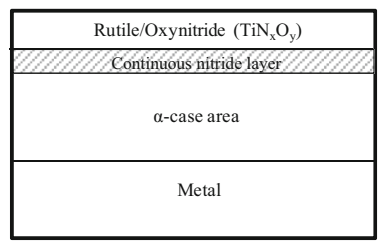

(c)

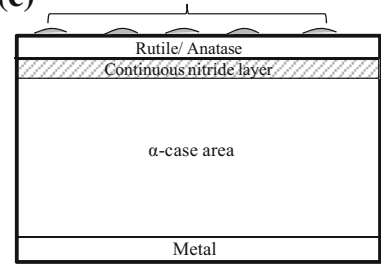

Fig. 8 Schematic cross section after $100 \mathrm{~h}$ of oxidation at $700{ }^{\circ} \mathrm{C}$ under air: a US, b LSP, and c SP30

adherence and less spallation were observed after oxidation for LSP. NRA analysis (Fig. 5) revealed a formation of large continuous nitride layer located between the oxide and the $\alpha$-case area. Nitrogen is also detected in the oxide layer for LSP samples, but in smaller quantities. Thus, the formation of oxynitride by nitrogen insertion in the oxide layer is also possible. For SP30 (schematic presented Fig. 7c), the oxide thickness is about $50 \%$ thinner than for untreated samples. Rather poor adherence of the oxide layer was also observed for SP30. The NRA analyses revealed a formation of continuous nitride layer between the oxide and the $\alpha$-case area. Also, the formation of anatase oxide phase is observed by Raman spectrometry (Fig. 4) and XRD analysis (Table 1). A surface pollution with $\mathrm{WO}_{3}$ clusters was noticed. By comparing the oxidation tests in dry air and pure oxygen (Fig. 3) (where the SP samples do not show any oxidation rate diminution), one can conclude that the nitrogen plays the main role in the mass gain reduction and not the tungsten carbide contamination.

From these observations, we propose then the following oxidation probable mechanism:

- The shot-peening and laser-shock peening introduce work-hardening and increase the grain boundary density for SP30 (Fig. 1). This produces shortcircuits of diffusion for light elements. The work hardening is proved by the micro-hardness tests. Thus, the effective diffusion coefficients of the light elements are increased. Gutman et al. [30] correlated the deformation effect with the chemical reaction. The plastic deformation increases the entropy of the system. The stresses generated on the sample sub-surface lead to surfacereaction acceleration.

- These short-circuits of diffusion allow the oxygen and nitrogen to penetrate easier the first few $\mu \mathrm{m}$. As an example, at $700{ }^{\circ} \mathrm{C}$, the estimated length of diffusion of $\mathrm{O}$ in Ti is about $5 \mu \mathrm{m}$. Some authors confirm this theory: Wen et al. [31] observe an increasing of oxygen, nitrogen, and carbon penetration under the surface after SMAT treatment and oxidation at $700{ }^{\circ} \mathrm{C}$ on pure Ti. Thomas et al. [32] shows that the oxygen content increases after shot-peening treatment and oxidation $1800 \mathrm{~h}$ under dry air at $700{ }^{\circ} \mathrm{C}$ on titanium IMI 834 alloy. The deeper penetration of oxygen into the metal for SP30 is confirmed by micro-hardness measurements (Fig. 6).

- Once the first layers are oxidized, the dense oxide scale let diffuse oxygen and nitrogen. Coddet et al. [4] noticed that nitrogen has a diffusion coefficient higher to those of oxygen through the $\mathrm{TiO}_{2}$. 
- Before defects are restored, a part of the oxygen passing through the oxide scale can continue to diffuse into the metal thanks to the augmented diffusion coefficients. This produces a decrease of the maximum oxygen concentration and consequently of the oxygen partial pressure, which slows down the oxidation rate. This produces a thinner oxide scale especially on SP30 samples where the density of defects is very important.

- Furthermore, the nitrogen that accumulates at the interface between oxide and metal cannot diffuse towards the core of the material as fast as the oxygen because its diffusion coefficient is ten times smaller [4, 33].

- This accumulation makes the formation of nitrides possible, which were revealed by the XRD analyses of samples oxidized for $5 \mathrm{~h}$ (Table 1). In the untreated samples case, the nitrides are more diluted or absent because at the beginning there is less nitrogen available and more oxygen, because the last one diffuses less in the absence of defects and accumulates more at the interface.

- The NRA results (Fig. 5) show that the nitrogen is mainly located at the interface between the oxide and metal. In the case of LSP and SP30, the layer is continuous, while in the untreated samples case, it is composed of plots. This layer can play an important role by creating a barrier for the oxygen diffusion, and also by changing the chemical conditions for the oxide formation. This intermediate scale, rich in nitrogen, can also play a role of accommodation layer between the oxide and the metal, which produces a better adherence of the oxide scale, less spallation, and then ensures the protective role of the oxide.

- We remarked thanks to the NRA that on LSP samples that the oxide scale contains non-negligible amounts of nitrogen (Fig. 5). This is probably true also on SP30, but is difficult to certify because of the small size of the oxide scale. This nitrogen can also modify the Pilling-Bedworth ratio within the oxide and then the stress state at the interface. The possibility of oxynitride formation could also explain the better adherence of the oxide layer [34]. After $2 \mathrm{~h}$ of oxidation at $850{ }^{\circ} \mathrm{C}$ for TA6V, Borgioli et al. [35] observed the formation of $\mathrm{TiN}_{x} \mathrm{O}_{y}$ in oxide layer and better adherence during tribological tests.

- One has to notice that the oxide nature, as well as the epitaxial stresses state, can also be modified by the texture of the material after treatment.

- The relatively good oxidation behavior of LSP in pure oxygen by comparison of the other samples (Fig. 3b) and reduction of $\alpha$-case area by comparison of untreated sample (Fig. 6) could suggest other effects than those cited here as particular epitaxy of the growing oxide or differences in the oxide morphology given by the mechanically impacted metal surface. Further works will focus on the oxide structure.

\section{Conclusions}

The present study shows that shot-peening and laser-shock peening slow down the high-temperature oxidation rate of pure Ti. The mass gain is reduced by about 10 and $45 \%$ for LSP and SP30, respectively. The understanding of the oxidation 
mechanisms can help to optimize the treatments in order to improve the hightemperature behavior of this material.

The study of the oxide scale thickness, its phase structures, as well the oxygen and nitrogen distribution was performed, and a schematic mechanism for hightemperature oxidation of shot-peened and laser-shock peened titanium was proposed. The role of the nitrogen in the oxidation resistance of the shot-peened and laser-shock peened samples was revealed. For LSP, another effect is also possible: epitaxy of the growing oxide by example.

An oxidation model for shot-peened and laser-shock peened samples was proposed here.

The next works will focus on longer oxidation periods, compatibles with industrial requirements.

\section{References}

1. J. C. William and E. A. Starke, Acta Materialia 51, 5775 (2003).

2. J. Stringer, Acta Metallurgica 8, 758 (1960).

3. A. M. Chaze and C. Coddet, Journal of the Less Common Metals 124, 73 (1986).

4. C. Coddet, A. M. Chaze, and G. Beranger, Journal of Materials Science 22, 2969 (1987).

5. D. K. Das and S. P. Trivedi, Material Science and Engineering 367, 225 (2004).

6. M. D. Alam and D. K. Das, Surface and Coating Technology 128-129, 89 (2009).

7. I. Gurappa, D. Manova, J. W. Gerlach, S. Mandl, and B. Raushenbach, Surface and Coating Technology 201, 3536 (2006).

8. A. K. Lal, S. K. Sinha, P. K. Bahrai, K. G. M. Nair, S. Kavalathy, and D. C. Kothari, Surface and Coating Technology 203, 2605 (2009).

9. A. Ebach-Stahl, C. Eilers, and N. Laska, Surface and Coating Technology 223, 24 (2013).

10. D. Wei, P. Zhang, Z. Yao, and J. Zhou, Surface and Coating Technology 204, 2343 (2012).

11. M. C. Marco de Lucas, L. Lavisse, and G. Pillon, Tribology International 41, 985 (2008).

12. V. Optasanu, P. Jacquinot, and T. Montesin, Advanced Materials Research 996, 912 (2014).

13. L. Raceanu, V. Optasanu, T. Montesin, and M. François, Oxidation of Metals 79, 135 (2013).

14. M. Micoulaut, S. Mechkov, D. Retraint, P. Viot, and M. François, Granular Matter 9, 25 (2005).

15. K. Y. Zhu, A. Vassel, F. Brisset, K. Ju, and J. Lu, Acta Materalia 52, 4101 (2004).

16. P. Peyre, L. Berthe, V. Vignal, I. Popa, and T. Baudin, Journal of Physics 45, 335304 (2012).

17. P. Peyre, C. Carboni, P. Forget, G. Beranger, C. Lemaître, and D. Stuart, Journal of Material Science 42, 6866 (2007).

18. H. Khodja, E. Berthoumieux, L. Daudin, and J. P. Gallien, Nuclear Instruments and Methods in Physics Research Section B 181, 83 (2001).

19. A. Gurbich and S. Molodtsov, Nuclear Instruments and Methods in Physics Research Section B 266, 1206 (2008).

20. L. Lavisse, P. Berger, M. Cirisan, J. M. Jouvard, S. Bourgeois and M. C. Marco de Lucas, Journal of Physics D 42, 245303 (2009).

21. J. M. Chappé, M. C. Marco de Lucas, L. Cunha, C. Moura, J. F. Pierson, L. Imhoff, O. Heintz, V. Potin, S. Bourgeois, and F. Vaz, Thin Solid Films 520, 144 (2011).

22. H. E. Evans, International Materials Reviews 40, 1 (1995).

23. M. Boulova and G. Lucazeau, Journal of Solid State Chemistry 167, 425 (2002).

24. W. Jia, Q. Hong, H. Zhao, L. Li, and D. Han, Material Science and Engineering 606, 354 (2014).

25. Z. Cao, H. Xu, S. Zou, and Z. Che, Chinese Journal of Aeronautics 25, 650 (2012).

26. X. C. Zhang, Y. K. Zhang, J. Z. Lu, F. Z. Xuan, Z. D. Wang, and S. T. Tu, Materials Science and Engineering 527, 3411 (2010).

27. C. Cellard, D. Retraint, M. François, E. Rouhaud, and D. Le Saunier, Materials Science and Engineering 532, 362 (2012). 
28. S. B. Fard and M. Guagliano, Frattura e Integrita Strutturale 7, 3 (2009).

29. M. Thomas and M. Jackson, Scripta Materialia 66, 1065 (2012).

30. E. M. Gutman, Mechanochemistry of Solid Surface (World Scientific, Singapore, 1994).

31. M. Wen, C. Wen, P. Hodgson, and Y. Li, Colloids and Surfaces B 116, 658 (2014).

32. M. Thomas, T. Lindley, D. Rugg, and M. Jackson, Acta Materialia 60, 5040 (2012).

33. A. Antilla, J. Räisänen, and J. Keinonen, Applied Physics Letters 42, 498 (1983).

34. F. Torrent, L. Lavisse, P. Berger, G. Pillon, C. Lopes, F. Vaz, and M. C. Marco de Lucas, Surface and Coatings Technology 255, 146 (2014).

35. F. Borgioli, E. Galvanetto, F. Iozelli, and G. Pradelli, Materials Letters 59, 2159 (2005). 